\title{
USO DE ANTIMICROBIANOS NA SUINOCULTURA: INDICAÇÕES E RESTRIÇÕES
}

\author{
Ariel Eurides Stella ${ }^{1}$ \\ Angélica Franco de Oliveira ${ }^{2}$ \\ Cecília Nunes Moreira ${ }^{3}$ \\ Kevin Guilherme Viali ${ }^{4}$
}

\begin{abstract}
RESUMO
Os antimicrobianos são utilizados na produção animal desde a década de 60, na suinocultura de quatro maneiras diferentes: como promotores de crescimento, profiláticos, metafiláticos e terapêuticos. O uso indiscriminado, aliado a subdosagens, classes erradas e destino inadequado de resíduos representam problema não só para produtores e trabalhadores da área, mas para a saúde pública e ambiental. Acredita-se que alternativas como a vigilância e o diagnóstico de uso na produção animal, bem como o levantamento e a promoção de um banco de dados para caracterizar, determinar ou restringir seu uso, podem reduzir a pressão de seleção para isolados resistentes e a incidência de genes de resistência. Algumas alternativas para a diminuição do uso de antimicrobianos estão ligadas a qualidade sanitária dos rebanhos, englobando aspectos como biosseguridade, utilização de programa vacinal completo e promoção do bem-estar dos animais. Muitos países e organizações também estão promovendo políticas de controle do uso dessas substâncias na produção animal. A utilização de antimicrobianos na suinocultura tende a ser reduzida com base em campanhas de conscientização e treinamento dos produtores, alertando para o uso racional dos fármacos visando combater a resistência bacteriana e maximizando a eficiência terapêutica. Esta revisão busca elucidar as principais bases de uso de antimicrobianos na suinocultura brasileira, bem como seus possíveis impactos, restrições e alternativas.
\end{abstract}

Palavras-chave: Produção Animal, Antibióticos, Saúde Pública.

\section{USE OF ANTIMICROBIALS IN SWINE FARMING: INDICATIONS AND RESTRICTIONS.}

\begin{abstract}
Antimicrobials have been used in animal production since the 1960s, in pig farming in four different ways - as growth promoters, prophylactics, metaphylactics and therapeutics. The indiscriminate use, combined with underdoses, wrong classes and inadequate waste destination are a problem not only for producers and workers in the area, but for public and environmental health. It is believed that alternatives such as surveillance and diagnosis of use in animal production, as well as, the survey and promotion of a database to characterize, determine or restrict its use, may reduce the incidence of resistance genes. Some alternatives for reducing their use are linked to the health quality of the herd, encompassing aspects such as biosecurity, use of a complete vaccination program and promotion of animal welfare. Many countries and organizations are also promoting policies to control the use of these substances in animal production. The use of antimicrobials in swine tends to be reduced through awareness and training of producers, alerting to the rational use of these drugs in
\end{abstract}


order to fight bacterial resistance and take advantage of their efficiency in a safe manner. This review seeks to elucidate some points of the use of antimicrobials in Brazilian pig farming, as well as their possible impacts, restrictions and alternatives.

Keywords: Animal Production, Antibiotics, Public Health.

\section{USO DE ANTIMICROBIANOS EN PORCINADO: INDICACIONES Y RESTRICCIONES.}

\section{RESUMEN}

Los antimicrobianos se han utilizado en la producción animal desde la década de 1960, en la cría de cerdos de cuatro formas diferentes: como promotores del crecimiento, profiláctica, metafiláctica y terapéutica. El uso indiscriminado, combinado con infradosificaciones, clases equivocadas y un destino inadecuado de los residuos representan un problema no solo para los productores y trabajadores de la zona, sino para la salud pública y ambiental. Se cree que alternativas como vigilancia y diagnóstico de uso en producción animal, así como el relevamiento y promoción de una base de datos para caracterizar, determinar o restringir su uso, pueden reducir la presión de selección de aislamientos resistentes y la incidencia de genes de resistencia. Algunas alternativas para reducir el uso de antimicrobianos están vinculadas a la calidad sanitaria de los rebaños, englobando aspectos como la bioseguridad, el uso de un programa completo de vacunación y la promoción del bienestar animal. Muchos países y organizaciones también están promoviendo políticas para controlar el uso de estas sustancias en la producción animal. El uso de antimicrobianos en la cría de cerdos tiende a reducirse en base a campañas de concientización y capacitación a los productores, alertando sobre el uso racional de medicamentos para combatir la resistencia bacteriana y maximizando la eficiencia terapéutica. Esta revisión busca dilucidar las principales bases para el uso de antimicrobianos en la cría de cerdos brasileña, así como sus posibles impactos, restricciones y alternativas.

Palabras clave: Producción animal, antibióticos, salud pública.

\section{INTRODUÇÃO}

A carne suína apresenta papel de destaque no consumo mundial geral de proteínas de origem animal. Neste contexto, o Brasil é importante produtor e exportador mundial de carne suína. Esta produção vem evoluindo para atender a demanda com sistemas cada vez mais intensivos de criação, e requerendo cada vez mais mão-de-obra especializada para suprir as necessidades do setor produtivo. No passado o sistema produtivo de suínos era do tipo "ciclo completo", em que todas as fases eram alojadas em um sítio único. Entretanto, esse cenário vem mudando para sistemas complexos de dois, três ou quatro sítios, ou mesmo para sistemas mais sofisticados (1). Esta intensificação gerou necessidade de aumento da utilização de antimicrobianos, pois animais criados em alguns tipos de instalações não têm contato com micro-organismos de outras áreas do ciclo de produção. Além disso, o aumento da densidade pode produzir estresse e, consequentemente, imunossupressão, contribuindo para o surgimento de micro-organismos potencialmente patogênicos e resistentes para os animais. $\mathrm{O}$ crescente problema da resistência bacteriana aos antimicrobianos tem sido relacionado, entre outros fatores, ao uso extensivo dos fármacos na suinocultura convencional (2). Quando se compara a resistência aos antimicrobianos da população intestinal bacteriana, se observa que 
é maior em bactérias de suínos convencionais que em animais criados em sistemas orgânicos (3).

O modelo de produção de suínos no Brasil conta com granjas de grande porte e alta densidade favorecendo que os suínos infectados entrem em contato direto com suínos susceptíveis, dificultando o controle das enfermidades, além do alto custo com o uso de antimicrobianos na forma de pulsos preventivos ou metafiláticos nas dietas ou na água destes animais. Diferentes antimicrobianos são rotineiramente utilizados na suinocultura. Os grupos de penicilinas e tetraciclinas são os antimicrobianos mais usados em muitos países, principalmente por via oral nos períodos de aleitamento e pós-desmame (4).

Os antimicrobianos são, provavelmente, a família mais bem sucedida de fármacos desenvolvidos para melhorar a saúde humana. Além disso, são utilizados em larga escala para tratar infecções em animais e, consequentemente, garantir bom rendimento de ganho de peso $(5,6)$. Os antimicrobianos têm sido usados rotineiramente na produção de animais de criação desde os anos 50, a fim de manter os animais saudáveis e aumentar a produtividade. Entretanto, este uso levantou preocupações de que a pressão seletiva na população de bactérias poderia promover resistência aos medicamentos (4). Apesar disso, em grande parte do mundo, os antimicrobianos não são regulamentados e são usados de forma indiscriminada, bem como, raramente existem estatísticas de uso (7). Ainda, muitas vezes são utilizados antimicrobianos de categorias criticamente importantes para humanos, como a colistina (8). No Brasil, a produção animal em sua forma atual, é bastante dependente do uso de antimicrobianos para melhorar a saúde animal e garantir ganho de peso adequado durante o ciclo produtivo. Entretanto, Diana et al. (9) sugeriram que a remoção dos antimicrobianos profiláticos na alimentação de suínos é possível, e que as reduções no desempenho produtivo e na saúde, podem ser minimizadas pela melhoria do manejo e uso de antimicrobianos parenterais.

Existem quatro abordagens terapêuticas para o uso de antimicrobianos na suinocultura, que se diferenciam pelos objetivos de uso, dose e duração de tratamento: 1)uso profilático de forma individual ou em rebanho, 2) o uso metafilático pelo tratamento de todo o lote em risco, prevenindo de forma grupal a disseminação do agente infeccioso assim que alguns animais adoecem, 3) uso terapêutico nos animais doentes, 4) promotores de crescimento, que consistem na utilização de baixas doses por longos períodos visando a modulação da microbiota intestinal e o ganho de desempenho (conversão alimentar e ganho de peso diário) (10). Ainda, se utilizam antimicrobianos sob a forma de "pulsos", no decorrer da produção, para proteger o animal que passou por estresse de viagem, instalações com alto nível de pressão de infecção, elevada densidade, má qualidade nutricional, introdução de patógenos e outros fatores imunossupressores. Por muitos anos, foram defendidos os efeitos positivos da prática da administração de sub dosagens de antimicrobianos para a promoção do ganho de peso em aves domésticas, suínos e gado de corte, negligenciando as consequências de aumento da pressão seletiva para bactérias resistentes (7).

Vários fatores estão ligados a administração de antimicrobianos em suínos, incluindo a faixa etária dos animais, posto que se utiliza no período de desmame (11). A quantidade de animais medicados e a resposta desejada são critérios de avaliação. A administração individual via parenteral visa resposta considerada mais rápida e não há necessidade de medicar muitos animais. Em contraste, a administração por via oral por água através de sistema dosador ou por ração, possui maior praticidade e eficiência em terapias em massa, porém não se garante que cada animal receba a dose correta. Os sistemas de águas por outro lado, estão propensos ao desenvolvimento de biofilmes bacterianos (12). Portanto, a limpeza das linhas de água é importante para a eficácia do tratamento proposto, pois a contaminação pode inibir os efeitos benéficos. Uma vantagem desse sistema via hídrica é que a redução da ingestão de água nos animais doentes é menos significativa do que a queda da ingestão de 
ração (1). O problema não está ligado apenas à quantidade total de antimicrobiano utilizado em ambiente particular, ou qual antimicrobiano está sendo utilizado, mas quantos indivíduos estão consumindo o fármaco na concentração adequada. Além disso, a via aplicada pode influenciar a taxa de eliminação dos resíduos de antimicrobianos pelas fezes e urina dos animais (13). Toda esta prática depende de pessoal capacitado, embora por vezes, estes são pouco informados dos riscos do uso não racional dos antimicrobianos na suinocultura (2).

$\mathrm{O}$ uso de antimicrobianos é requerido por doenças específicas da idade e pelos patógenos comuns que causam essas condições, que variam entre os países. Além disso, o tipo e tamanho das criações estão associados ao uso de antimicrobianos, pois granjas maiores usam mais medicamentos que criatórios menores (4). A escolha de um antimicrobiano se fundamenta na obtenção de diagnóstico preciso do agente causal da doença que se pretende tratar ou prevenir (1). Essa tarefa é complexa devido a variedade de produtos no mercado. Portanto, a disposição de resultados de análises e testes de sensibilidade microbiana in vitro para determinar o agente e o perfil de sensibilidade, são de extrema importância para auxiliar no diagnóstico e tratamento. Quando não for possível o acesso a estes dados a escolha do antimicrobiano deve ser baseada na literatura científica. Além disso, o produtor pode utilizar antimicrobianos para ambos os fins, terapêuticos e não terapêuticos (7).

Diante do exposto, a presente revisão visa abordar os principais aspectos de uso de antimicrobianos na suinocultura brasileira, bem como impactos e restrições. Compreender o uso racional de antimicrobianos em animais de produção é essencial para abordagens terapêuticas e de controle/profilaxia.

\section{AMBIENTE E RESISTÊNCIA ANTIMICROBIANA}

A resistência aos antimicrobianos e seus resíduos é uma preocupação emergente, de ordem mundial. O conceito "One Health", promulgado por muitas agências globais de saúde, reconhece que a resistência antimicrobiana é um problema global no qual a saúde humana, a pecuária e o meio ambiente estão inter-relacionados (14). À semelhança dos metais pesados, os antimicrobianos são compostos naturais presentes em diferentes ecossistemas e, atualmente, também são considerados poluentes ambientais, uma vez que, sua utilização pelos humanos aumentou a sua biodisponibilidade, conduzindo a mudança dramática em ecossistemas poluídos (5). Nestes ambientes a seleção bacteriana é considerada processo natural que ocorre de várias formas. Entretanto, faz-se necessário conhecer o impacto desses poluentes sobre o surgimento de linhagens resistentes nestes ecossistemas, devido a utilização de antimicrobianos em sistemas de produção animal, como na suinocultura.

No que tange ao o potencial poluente dos antimicrobianos, estima-se que entre $25 \%$ e 75\% dos antimicrobianos administrados em animais de confinamento podem ser excretados inalterados nas fezes (15). Na China, Zhu et al. (16) alertaram que genes de bactérias resistentes aos antimicrobianos podem ser dispersos pelo ambiente chegando até a contaminar culturas de arroz e trigo adubadas com esterco.

Segundo Pruden et al. (17) é necessária gestão de controle de escoamento e atualizações de infraestruturas de tratamento de águas residuais provenientes da produção de suínos, como a lama de criatórios resultante da mistura de fezes e água, que são destinadas para sistema de coleta para lagoas. O incentivo a construção de instalações de exploração de gases energéticos para tratamento de resíduos de dejetos, como biodigestores e o tratamento biológico desses dejetos como a compostagem, armazenamento e condições da lagoa de dejetos, reduzem os níveis de resíduos lançados ao meio ambiente. A utilização de biodigestores, além de fonte alternativa de energia para a propriedade e para o mercado financeiro pela venda de créditos de carbono, poderia proteger o meio ambiente e remover até $80 \%$ da carga orgânica dos dejetos, diminuindo os odores e eliminando micro-organismos causadores de doenças (18). 
Considera-se que três princípios podem influenciar na propagação de genes de resistência aos antimicrobianos (GRA) entre animais e humanos, a saber: baixas doses, a utilização não terapêutica e a resistência bacteriana em humanos causada pelos mesmos mecanismos que nos animais. Além disso os genes de resistência podem ser difundidos para a microbiota intestinal pela cadeia alimentar, pelo consumo de alimentos de origem animal (19). Portanto, a exposição a bactérias resistentes e seus genes no ambiente pode aumentar a prevalência de resistência no microbioma intestinal humano (20). O quadro se torna ainda mais complexo quando também consideramos que antimicrobianos podem afetar mais de uma espécie de micro-organismos, e que genes de resistência podem ser transmitidos entre bactérias (21).

Callens et al. (22) relataram em estudo, na Bélgica, que quase metade dos antimicrobianos orais eram utilizados em doses inadequadas e que os fármacos usados incluíram alguns antimicrobianos críticos para uso em humanos, como a colistina e a amoxicilina. Esta utilização inadequada de antimicrobianos, pode aumentar a ocorrência de bactérias multirresistentes na medicina humana, incluindo infecções nosocomiais. Um desafio importante também é a utilização excessiva e inadequada de antimicrobianos para infecções não bacterianas, tais como infecções virais (7), apesar do aumento dos critérios para aquisição e utilização de antimicrobianos.

Segundo Díaz-Quiroz et al. (6) resíduos de antimicrobianos são transportados para o ambiente em sua forma ativa em concentrações que podem induzir resistência em bactérias, que podem ser transferidas para patógenos humanos. As bactérias são capazes de transferir genes por vários mecanismos. Zhul et al. (23) afirmaram que a propagação de genes de resistência antimicrobiana está intimamente associada com elementos genéticos móveis como plasmídeos, integrons e transposons (genes saltadores). Um fator crucial na seleção de bactérias resistentes nos animais, se deve a concentração do antimicrobiano. A concentração inibitória mínima (CIM) é a menor concentração de um produto responsável por limitar a multiplicação de um microrganismo (12).

Segundo Dolliver e Gupta (24) a maioria dos antimicrobianos utilizados para prevenir ou tratar infecções em humanos ou animais, são apenas parcialmente metabolizados, e eliminados ativos nas excretas em esgotos, estações de tratamento de água e solos. Entretanto, o fato de que esses medicamentos são degradados em ecossistemas naturais e possuem meia vida, não significa que não sejam potenciais poluentes. Ainda, o aumento de concentrações de resíduos em ecossistemas naturais como consequência das atividades humanas, altera as funções originais dos antimicrobianos (5), impactando não somente a saúde humana mas também organismos aquáticos (25).

Propriedades produtoras de suínos são conhecidas como pontos de pressão de seleção para isolados resistentes, pela dispersão de genes de resistência aos antimicrobianos, expandindo a diversidade dessas linhagens e com potencial de transmissão para humanos pela alimentação. Os antimicrobianos podem permanecer nos tecidos dos animais, nos alimentos, bem como serem eliminados no ambiente pelas fezes e urina (13). Sugere-se que os antimicrobianos presentes em alimentos, água ou solo, possam alterar a microbiota, produzindo modificações ambientais locais que alteram sua composição como seleção de genes. Vale lembrar também, que os antimicrobianos podem produzir alterações transitórias que podem ser relevantes mesmo em baixas concentrações. Assim, além de controlar o uso de antimicrobianos, são necessários estudos para compreender a origem dos genes de resistência e melhorar a degradação dos resíduos de antimicrobianos utilizados. A terapêutica aplicada adequadamente para o tratamento individual de animais tende a controlar o surgimento e disseminação de isolados resistentes aos antimicrobianos, em grande parte devido à aplicação a curto prazo e em números relativamente pequenos de animais tratados (7). Preferir tratar animais individualmente a expor animais sadios aos antimicrobianos é uma boa alternativa. 
Paralelamente, a produção orgânica de suínos, difere de várias maneiras da produção convencional no uso dos antimicrobianos. Entretanto, este ponto é ligado também a diferentes estruturas dos rebanhos, regimes alimentares, acesso a áreas externas e espaço disponível por animal (3). Igualmente Tiedje et al. (14) referiram que são necessárias práticas que reduzam o uso de antimicrobianos e, consequentemente, a resistência bacteriana, bem como práticas que limitem a disseminação de patógenos resistentes e seus genes de resistência que, por vezes, permanecem viáveis no ambiente.

\section{IMPACTOS E AÇÕES}

Aliado às mudanças climáticas, o estresse hídrico e a degradação ambiental, a ampla resistência bacteriana aos antimicrobianos deve ser considerada como um dos desafios globais da humanidade neste século (14). A Organização Mundial de Saúde (OMS) estima que cerca de metade da quantidade dos antimicrobianos produzidos são utilizados em animais de produção (26), pelo uso em larga escala, como em granjas suinícolas. Ao contrário, os animais de companhia são medicados após avaliação clínica, possuem acompanhamento sistemático e rigoroso de médico veterinário e o tratamento é estabelecido depois de exclusões dos diagnósticos diferenciais. Na suinocultura, além dos animais que realmente necessitam, a administração dos fármacos pode ocorrer inadvertidamente em animais sadios como forma de controle e prevenção de doenças infectocontagiosas.

O impacto do uso indiscriminado de antimicrobianos, como ameaça para a saúde humana, tem sido objeto de grande discussão na comunidade científica (21). Além do uso em granjas produtoras de suínos, outros fatores como a globalização, ausência de saneamento básico e poluição ambiental de águas e solos podem influenciar na ocorrência da multirresistência bacteriana. A utilização de antimicrobianos para fins clínicos ou agropecuários pode, também, aumentar a pressão seletiva para bactérias multirresistentes. Assim, os diferentes resíduos, tanto de hospitais como fontes agropecuárias, possuem antimicrobianos livres e microrganismos com genes de resistência (27). Os humanos e os animais não são os únicos expostos a sofrerem as consequências da transferência de genes ligados a resistência bacteriana. As cianobactérias, responsáveis por mais de um terço do total de $\mathrm{O}_{2}$ produzido na atmosfera, estão sofrendo com a poluição ambiental, cujo impacto tem sérias consequências globais no ambiente (5).

Lekagul et al. (8) recomendaram a restrição progressiva do uso de antimicrobianos em suínos com base no uso de prescrições para controlar a distribuição de certos fármacos. Além disso, destacam a necessidade de políticas públicas visando melhorar o acesso dos agricultores aos conselhos de saúde animal e explorar intervenções alternativas. O uso de antimicrobianos promotores de crescimento (APC) foi proibido pela UE (União Europeia) em 2006, e muitos outros países têm restringido os APC (28). Esta proibição provocou aumento compensatório no uso metafilático e terapêutico. Como o comércio livre é cada vez maior entre os membros da UE, existe necessidade de monitorar a resistência bacteriana aos antimicrobianos e implementar políticas comuns sobre o uso de antimicrobianos (29). No Brasil, os produtos utilizados devem estar previamente autorizados pelo MAPA e deveriam ser comercializados e utilizados mediante a prescrição de um médico veterinário responsável. Os produtos não podem conter aditivos melhoradores de desempenho com o mesmo princípio ativo do medicamento de uso veterinário a ser incorporado. Os estabelecimentos que manipulam esse tipo de medicamento devem estar registrados no MAPA e seguir criteriosa limpeza de equipamentos para evitar contaminação cruzada (30).

A preocupação dos efeitos da utilização dos antimicrobianos na produção animal, se dá pela emergente seleção de bactérias potencialmente patogênicas e resistentes nos animais, e que podem causar infecções em humanos, incluindo Campylobacter jejuni, E. coli, 
Salmonella sp., Enterococcus faecium entre outros (5). Na Dinamarca, altos níveis de resistência a macrolídeos foram observados em Campylobacter coli de origem suína. Uma possível justificativa seria que, embora o uso de tilosina para a promoção de crescimento tenha sido descontinuada em 1999, este fármaco continua sendo amplamente utilizada terapeuticamente na produção de suínos (31). Contudo, o país faz frente a responsabilidade do uso de antimicrobianos na suinocultura, desenvolvendo um plano e roteiro de políticas de intervenção pela monitorização contínua, e determinação de metas de uso, reestruturação entre cadeias produtivas e valorização e conscientização da importância de limitar o uso dessas substâncias. A detecção do nível de resíduos eliminados pela urina dos animais antes do abate é uma alternativa interessante de monitoramento (32), bem como a análise de águas residuais das granjas (6).

No Brasil, foi proibida a importação e a fabricação de sulfato de colistina com a finalidade de aditivo zootécnico melhorador de desempenho na alimentação animal (33). A Portaria $\mathrm{n}^{\mathrm{o}}$ 171, de 13 de Dezembro de 2018 do MAPA, também prevê a possível proibição do uso dos antimicrobianos tilosina, lincomicina, virginiamicina, bacitracina e tiamulina com a finalidade de aditivos melhoradores de desempenho em animais produtores de alimentos (34). Entretanto, em recente publicação (portaria $\mathrm{n}^{\mathrm{o}}$ 110, de 23 de maio de 2019), são citados apenas, tilosina, lincomicina e tiamulina. Em adição, a consulta pública ainda está aberta para receber manifestações técnicas (35).

Nos países baixos, De Boer et al. (36) descreveram Staphylococcus aureus Resistentes à Meticilina (MRSA) em 12\% da carne bovina, vitela, cordeiro, carne suína, peru e frangos em mercado. Voss et al. (37) demonstraram a transmissão de MRSA entre animais e humanos, humanos e humanos, suínos e suinocultores, entre os membros de família de suinocultores e entre uma enfermeira e um paciente em hospital. Genes bacterianos relacionados com a resistência aos antimicrobianos, representam potencial risco em todo o mundo. Acredita-se que a atenção a saúde humana e a pecuária intensiva contribuam significativamente para o aumento da carga ambiental de genes de resistência (14). No entanto, na Europa, já se observa diminuição dos níveis de resistência observados após a redução do uso de antimicrobianos nos animais de produção.

Estudo sobre a produção de suínos criados com ou sem o consumo de cefalosporinas de terceira e quarta geração, incluindo os produtores e suas famílias, para detecção de E. coli produtoras de beta-lactamases de espectro estendido (ESBL), encontraram isolados resistentes em 13 de 177 amostras oriundas de animais que não consumiam antimicrobianos, enquanto que foram identificadas cepas resistentes em 50 das 162 das amostras oriundas de animais consumindo estes compostos. Além disso, foi detectada a dispersão dos mesmos genes de resistência entre as populações bacterianas nos animais e nos humanos (38). Já em Portugal, Fournier et al. (39) detectaram taxas alarmantes de micro-organismos produtores de betalactamases em granjas de suínos.

Considera-se que as principais vias de exposição humana aos genes de resistência antimicrobiana são os alimentos contaminados, como vegetais expostos a esterco ou águas residuais ou carnes contaminadas com resíduos fecais durante o abate (14).

Em nível global, o estabelecimento de acordos e protocolos internacionais poderia minimizar a disseminação de bactérias multirresistentes. Na UE, produtos de origem animal importados de países onde estes promotores de crescimento são utilizados livremente, devem seguir acordos internacionais para evitar a introdução de linhagens resistentes (29). O Brasil, que contém empresas exportadoras, para atender as exigências transnacionais e continuar com as exportações, está aderindo a estas políticas de desuso de antimicrobianos, principalmente no setor da produção de suínos.

\section{ESTRATÉGIAS PARA A REDUÇÃO DO USO}


É importante ressaltar, que as mudanças nas práticas de produção animal que reduzem o uso de antimicrobianos podem reduzir a seleção e a transmissão de bactérias resistentes pelos animais $(20,40)$. O benefício parece se estender aos agricultores e aqueles em contato direto com os animais, embora o efeito para a população humana em geral é menos claro (40). Entretanto, uma proibição total e imediata da utilização de antimicrobianos na suinocultura poderia trazer inevitavelmente repercussões graves para a saúde animal e a produtividade, bem como nos preços finais dos produtos.

O desuso deve ser estabelecido de forma estratégica aliado com medidas que reforcem a qualidade sanitária do rebanho, para não comprometer a economia da atividade. Rojo-Gimeno et al. (41) referiram que é possível a redução no uso de antimicrobianos sem prejudicar o lucro das empresas. A proposição prática mais imediata pode ser a de ampliar a gama de vacinas disponíveis para uso veterinário. Neste contexto, ensaio de vacina oral viva contra a Lawsonia intracellularis em suínos, resultou em $80 \%$ menos consumo de oxitetraciclina e ao aumento da produtividade (42).

$\mathrm{Na}$ Alemanha, o nível de biossegurança de um rebanho foi associado à quantidade de antimicrobianos utilizados. Os achados deste estudo indicaram possíveis pontos de ação na redução e uso prudente de antimicrobianos. Os autores sugerem que a melhoria das medidas de biossegurança pode ser uma alternativa promissora para reduzir o uso de antimicrobianos nos rebanhos (43).

É necessária uma visão ampla para minimizar o uso de antimicrobianos nas granjas, que deve ser realizado em conjunto com as mudanças nos sistemas de produção que minimizam as doenças e mantêm a lucratividade do agricultor (20), que inclui o controle de vetores, roedores e animais selvagens que são fontes de transmissão de patógenos aos suínos por exemplo. Também é fundamental controlar os animais de reposição, sêmen, bem como a movimentação dos funcionários da granja, como o compartilhamento de equipamentos e materiais, responsáveis pela disseminação de agentes infecciosos. O uso de baias de enfermarias pode também segregar parcialmente os suínos doentes do resto do grupo (44). Há necessidade de atenção especial com esses animais, pois o fato de estarem com a doença clinicamente visível significa que são grande fonte de infecção para os animais saudáveis.

Outro importante fator para o aparecimento de linhagens resistentes é a permanência de agentes infeciosos na matéria orgânica, que permanece nas instalações devido à insuficiente remoção (45). A limpeza e desinfecção inadequada de instalações, em consequência da diversidade de micro-organismos, favorece a disseminação de resistência bacteriana. Determinar um protocolo eficaz de sanitização das instalações e utilizar detergentes e desinfetantes adequados reduz a prevalência de patógenos. A lavagem e desinfecção correta das instalações e utensílios diminui a quantidade de microrganismos e, portanto, diminui a pressão de infecção, resultando em menor quantidade de animais doentes. Luyckx et al. (46) comparou o período de vazio sanitário de salas de creche de suínos e determinou que os melhores resultados foram obtidos com vazios entre 4 e 7 dias. O prolongamento superior a dez dias de tempo de vazio gerou efeitos negativos financeiramente e de contaminação bacteriana.

Não existe um plano de biosseguridade polivalente que possa ser adotado em todas as granjas, uma vez que existem variações em termos de localização, instalações, manejo, nutrição, ambiência, genética e assistência técnica disponíveis (44). Apesar da disponibilidade de muitas vacinas, os imunógenos não controlam todos os micro-organismos, além disso, as vacinas devem ser competitivas em termos de custos para causar impacto no uso dos antimicrobianos (20).

Medidas devem ser tomadas em relação ao uso de antimicrobianos na suinocultura com intuito de evitar as perdas que a substituição desses animais possa causar sem planejamento 
adequado. Postma et al. (47) pontuam que é possível reduzir o uso de antimicrobianos criando-se uma estratégia para uso, otimizando o manejo do rebanho, o nível de biosseguridade e a elaboração de programas vacinais. Cheng et al. (25) também citaram a biossegurança e as vacinações como alternativas para a diminuição do uso. Algumas das estratégias que podem ser utilizadas para diminuir a utilização de antimicrobianos na suinocultura estão presentes na tabela 1.

A suplementação dietética também pode ser uma alternativa ao uso dos antimicrobianos em suínos, como a inclusão de prebióticos, probióticos e ácidos orgânicos na dieta. Os prebióticos são componentes de alimentação que modulam a microbiota intestinal para beneficiar a saúde do hospedeiro, tais como a exclusão competitiva de organismos patogénicos ou a estimulação de metabolitos de promoção da saúde, como fibras alimentares e oligossacarídeos (48). Os probióticos conferem benefícios análogos aos prebióticos, embora sejam organismos vivos como Lactobacillus spp. Já os ácidos orgânicos têm como característica principal diminuir o $\mathrm{pH}$ do meio, o que limitaria a deterioração de alimentos e resultaria em menor sobrevivência de agentes patogênicos (49). Uma alternativa promissora a substituição de antimicrobianos na dieta dos suínos são os óleos essenciais (50).

Paralelamente, a fagoterapia consiste na utilização de vírus bacteriófagos para invadir/eliminar bactérias específicas ou grupos de bactérias (49).

Fatores imunossupressores como o estresse impactam diretamente na utilização dos antimicrobianos. Portanto, um desafio importante é manter o animal saudável, respeitando o princípio das cinco liberdades determinadas pelo Conselho do Bem-estar dos Animais de Produção (FAWC). Partindo desse pressuposto, as instalações, condições ambientais de temperatura, qualidade do ar, disponibilidade de água potável e ração balanceada e de qualidade, densidade animal, cumprimento mínimo dos manejos básicos, enriquecimento ambiental, atendimento rápido e especial aos animais doentes e tratamento gentil são condições de criação ligadas ao bem-estar que favorecem qualidade de vida aos animais.

Muitos problemas de estresse estão ligados ao confinamento, alta densidade e a inviabilidade do animal de expressar seus comportamentos naturais. Uma forma de diminuir o estresse dos suínos é pelo enriquecimento ambiental. Este efeito deve ser analisado a partir de diferentes ângulos como aspectos comportamentais, fisiológicos e neurológicos. Fornecer, palha, madeira, feno, serragem, correntes, cordas, além de brinquedos de plástico, borracha, aromatizados e mastigáveis nas baias diminui a ociosidade e aumentam interações sociais entre os suínos (51). Portanto, a viabilidade da redução do uso, do ponto de vista produtivo e sanitário, somente poderá ser alcançada com maciços para aumentar o grau de bem estar animal nas granjas. Visschers et al. (2) sugeriram que a promoção de hábitos que reduzam o uso de antimicrobianos pelos agricultores e a conscientização destes sobre os riscos relacionados a esta prática na criação de suínos pode reduzir o uso dessas substâncias (40).

\section{CONCLUSÕES}

Com o passar do tempo a suinocultura foi se tornando cada vez mais intensiva, objetivando a produção de grandes quantidades de alimentos acessíveis a toda a população, e mantendo a rentabilidade do sistema produtivo. Entretanto esse modelo criou um ambiente muito desafiador a manutenção da sanidade desses animais. Consequentemente iniciou-se a utilização de grandes quantidades de antimicrobianos nos ciclos de produção, e isto pode estar desencadeando o aparecimento de isolados multirresistentes nesses ambientes. Este modelo vem sendo questionado e alternativas ao uso de antimicrobianos vem sendo desenvolvidas em todo o mundo. As principais práticas a serem utilizadas para a diminuição do uso de antimicrobianos na suinocultura incluem aspectos de bem estar animal, vacinações e a biosseguridade em geral. 


\section{REFERÊNCIAS}

1. Barcellos DESN, Marques BMFPP, Mores TJ, Coelho CF, Borowski SM. Aspectos práticos sobre o uso de antimicrobianos em suinocultura. Acta Sci Vet. 2009;37:151-5.

2. Visschers VH, Iten DM, Riklin A, Hartmann S, Sidler X, Siegrist M. Swiss pig farmers' perception and usage of antibiotics during the fattening period. Livest Sci. 2014;162:22332.

3. Osterberg J, Wingstrand A, Nygaard JA, Kerouanton A, Cibin V, Barco L, et al. Antibiotic resistance in Escherichia coli from pigs in organic and conventional farming in four European countries. PloS One. 2016;11:e0157049.

4. Lekagul A, Tangcharoensathien V, Yeung S. Patterns of antibiotic use in global pig production: a systematic review. Vet Anim Sci. 2019;7:100058.

5. Martinez JL. Environmental pollution by antibiotics and by antibiotic resistance determinants. Environ Pollut. 2009;157:2893-902.

6. Díaz-Quiroz CA, Hernandez-Chavez JF, Ulloa-Mercado G, Gortáres-Moroyoqui P, Martínez-Macías R, Meza-Escalante E, et al. Simultaneous quantification of antibiotics in wastewater from pig farms by capillary electrophoresis. J Chromatogr B. 2018;1092:38693.

7. Marshall BM, Levy SB. Food animals and antimicrobials: impacts on human health. Clin Microbiol Rev. 2011;24:718-33.

8. Lekagul A, Tangcharoensathien V, Mills A, Rushton J, Yeung S. How antibiotics are used in pig farming: a mixed-methods study of pig farmers, feed mills and veterinarians in Thailand. BMJ Glob Health. 2020;5:e001918.

9. Diana A, Boyle LA, Leonard FC, Carroll C, Sheehan E, Murphy D, et al. Removing prophylactic antibiotics from pig feed: how does it affect their performance and health? BMC Vet Res. 2019;15:67.

10. Dias AC, Carraro BZ, Dallanora D, Coser FJ, Machado GS, Machado IP, et al. Manual brasileiro de boas práticas agropecuárias na produção de suínos. Concórdia: Embrapa Suínos e Aves; 2011.

11. EMA Committee for Medicinal Products for Veterinary Use (CVMP) and EFSA Panel on Biological Hazards (BIOHAZ), Murphy D, Ricci A, Auce Z, Beechinor JG, Bergendahl $\mathrm{H}$, et al. EMA and EFSA Joint Scientific Opinion on measures to reduce the need to use antimicrobial agents in animal husbandry in the European Union, and the resulting impacts on food safety (RONAFA). EFSA J. 2017;15:e04666.

12. Meek RW, Vyas H, Piddock LJV. Nonmedical uses of antibiotic: time to restrict their use? Plos Biol. 2015;13:1-11. 
13. Qiu J, Zhao T, Liu Q, He J, He D, Wu G, et al. Residual veterinary antibiotics in pig excreta after oral administration of sulfonamides. Environ Geochem Health. 2016;38:549-56.

14. Tiedje JM, Fang WANG, Manaia CM, Virta M, Sheng H, Liping MA, et al. Antibiotic resistance genes in the human-impacted environment: a one health perspective. Pedosphere. 2019;29:273-82.

15. Chee-sanford JC, Aminov RI, Krapac IJ, Garrigues-jeanjean N, Mackie RI. Occurrence and diversity of tetracycline resistance genes in lagoons and groundwater underlying two swine production facilities. Appl Environ Microbiol. 2001;67:1494-502.

16. Zhu D, Giles M, Yang XR, Daniell T, Neilson R, Zhu YG. Phyllosphere of staple crops under pig manure fertilization, a reservoir of antibiotic resistance genes. Environ Pollut. 2019;252:227-35.

17. Pruden A, Larsson DGJ, Amézquita A, Collignon P, Brandt KK, Graham DW, et al. Management options for reducing the release of antibiotics and antibiotic resistance genes to the environment. Environ Health Perspect. 2013;121:878-85.

18. Dalmazo GS, Bazi SM, Oliveira PAV. Biodigestores. In: Dia de Campo Suinocultura e Meio Ambiente: Termo de Compromisso de Ajustamento de Condutas da Suinocultura, Concórdia. Suinocultura e Meio Ambiente; 2009; Concórdia. Concórdia: Embrapa Suínos e Aves; 2009.

19. Cogliani C, Goossens H, Greko C. Restricting antimicrobial use in food animals: lessons from Europe. Microbe. 2011;6:274-9.

20. Leonard AF, Zhang L, Balfour AJ, Garside R, Gaze HW. Human recreational exposure to antibiotic resistant bacteria in coastal bathing waters. Environ Int. 2015;82:92-100.

21. Woolhouse M, Ward M, Van bunnik B, Farrar J. Antimicrobial resistance in humans, livestock and the wider environment. Philos Trans R Soc B Biol Sci. 2015;370:1-7.

22. Callens B, Persoons D, Maes D, Laanen M, Postma M, Boyen F, et al. Prophylactic and metaphylactic antimicrobiial use in Belgian fattening pig herds. Prev Vet Med. 2012;106:53-62.

23. Zhu YG, Johnson TA, Su JQ, Qiao M, Guo GX, Stedtfeld RD, et al. Diverse and abundant antibiotic resistance genes in Chinese swine farms. Proc Natl Acad Sci USA. 2013;110:3435-40.

24. Dolliver H, Grupta S. Antibiotic losses in leaching and surface runoff from manureamended agricultural land. J Environ Qual. 2008;37:1227-37.

25. Cheng D, Ngo HH, Guo W, Chang SW, Nguyen DD, Liu Y, et al. A critical review on antibiotics and hormones in swine wastewater: water pollution problems and control approaches. J Hazard Mater. 2020;387:121682. 
26. World Health Organization. WHO guidelines on use of medically important antimicrobials in food-producing animals. Geneva: WHO; 2017.

27. Teuber M. Veterinary use and antibiotic resistance. Curr Opin Microbiol. 2001;4:493-9.

28. Barton MD. Impact of antibiotic use in the swine industry. Curr Opin Microbiol. 2014;19:9-15.

29. Garcia-Migura L, Hendriksen RS, Fraile L, Aarestrup FM. Antimicrobial resistance of zoonotic and commensal bacteria in Europe: the missing link between consumption and resistance in veterinary medicine. Vet Microbiol. 2014;170:1-9.

30. Brasil. Ministério da Agricultura, Pecuária e Abastecimento. Instrução Normativa $n^{\circ} 14$, de 15 de Julho de 2016. Aborda o regulamento técnico sobre os procedimentos para a fabricação e o emprego de produtos destinados à alimentação animal com medicamento de uso veterinário e os critérios para manipulação. Diário Oficial da União. 18 Jul 2016.

31. Juntunen P, Heiska H, Olkkola S, Myllyniemi AL, Hännienen ML. Antimicrobial resistance in Campylobacter coli selected by tylosin treatment at a pig farm. Vet Microbiol. 2010;146:90-7.

32. Chiesa L, Nobile M, Arioli F, Britti D, Trutic N, Pavlovic R, et al. Determination of veterinary antibiotics in bovine urine by liquid chromatography-tandem mass spectrometry. Food Chem. 2015;185:7-15.

33. Brasil. Ministério da Agricultura, Pecuária e Abastecimento. Instrução Normativa $n^{\circ} 45$, de 22 de Novembro de 2016. Dispõe sobre a proibição da substância antimicrobiana sulfato de colistina na alimentação animal. Diário Oficial da União. 30 Nov 2016.

34. Brasil. Ministério da Agricultura Pecuária e Abastecimento. Portaria $\mathrm{n}^{\mathrm{o}} 171$, de 13 de Dezembro de 2018. Dispõe sobre a intensão de proibição de cinco antimicrobianos como melhoradores de desempenho de animais produtores de alimentos. Diário Oficial da União. 19 Dez 2018.

35. Brasil. Ministério da Agricultura Pecuária e Abastecimento. Portaria $n^{\circ} 110$, de 23 de Maio de 2019. Dispõe sobre a proibição em território nacional a importação, fabricação e comercialização do uso de aditivos como melhoradores de desempenho que contenham tilosina, lincomina e tiamulina. Diário Oficial da União. 11 Jul 2019.

36. De Boer E, Zwartkruis-nahuis JTM, Huijsdens XW, Neeling AJ, Bosch T, Van Oosterom RAA, et al. Prevalence of methicillin-resistant Staphylococcus aureus in meat. Int J Food Microbiol. 2009;134:5256.

37. Voss A, Loeffen F, Brakker J, Klaassen C, Wulf M. Methicillin-resistant Staphylococcus aureus in Pig Farming. Emerg Infect Dis. 2005;11:1965-6.

38. Hammerum AM, Larsen J, Andersen VD, Lester CH, Skytte TSS, Hansen F, et al. Characterization of extended-spectrum ßlactamase (ESBL)-producing Escherichia coli obtained from Danish pigs, farmers and their families from farms with high or no 
consumption of third- or fourth-generation cephalosporins. J Antimicrob Chemother. 2014;69:2650-7.

39. Fournier C, Aires-de-sousa M, Nordmann P, Poirel L. Occurrence of CTX-M-15-and MCR-1-producing Enterobacterales in pigs in Portugal: Evidence of direct links with antibiotic selective pressure. Int J Antimicrob Agents. 2020;55:105802.

40. Tang KL, Caffrey NP, Nóbrega DB, Cork SC, Ronksley PE, Barkema HW, et al. Restricting the use of antibiotics in food-producing animals and its associations with antibiotic resistance in food-producing animals and human beings: a systematic review and meta-analysis. Lancet Planet Health. 2017;1:e316-27.

41. Rojo-Gimeno C, Postma M, Dewulf J, Hogeveen H, Lauwers L, Wauters E. Farmeconomic analysis of reducing antimicrobial use whilst adopting improved management strategies on farrow-to-finish pig farms. Prev Vet Med. 2016;129:74-87.

42. Bak H, Rathkjen PH. Reduced use of antimicrobials after vaccination of pigs against porcine proliferative enteropathy in a Danish SPF herd. Acta Vet Scand. 2009;51:1.

43. Raasch S, Postma M, Dewulf J, Stärk KDC, Grosse Beilage E. Association between antimicrobial usage, biosecurity measures as well as farm performance in German farrow-to-finish farms. Porcine Health Manag. 2018;4:30.

44. Heck A. Biosseguridade na suinocultura: aspectos práticos. In: Anais do 5o Seminário Internacional de Aves e Suínos; 2005; Florianópolis. Florianópolis: AveSui, Gesulli; 2005 .

45. Luyckx K, Millet S, Van Weyenberg S, Herman L, Heyndrickx M, Dewulf J, et al. Comparison of competitive exclusion with classical cleaning and disinfection on bacterial load in pig nursery units. BMC Vet Res. 2016;12:1-10.

46. Luyckx K, Millet S, Van Weyenberg S, Herman L, Heyndrickx M, Dewulf J, et al. A 10day vacancy period after cleaning and disifection has no effect on the bacterial load in pig nursery units. BMC Vet Res. 2016;12:236.

47. Postma M, Vanderhaeghen W, Sarrazin S, Maes D, Dewulf J. Reducing antimicrobial usage in pig production without jeopardizinh production parameters. Zoonoses Public Health. 2017;64:63-74.

48. Pan L, Zhao PF, Ma XK, Shang QH, Xu YT, Long SF, et al. Probiotic supplementation protects weaned pigs against enterotoxigenic Escherichia coli K88 challenge and improves performance similar to antibiotics. J Anim Sci. 2017;95:2627-39.

49. Allen HK, Levine UY, Looft T, Bandrick M, Casey TA. Treatment, promotion, commotion: antibiotic alternative in food-producing animals. Trends Microbiol. 2013;21:114-9.

50. Omonijo FA, Ni L, Gong J, Wang Q, Lahaye L, Yang C. Essential oils as alternatives to antibiotics in swine production. Anim Nutr. 2018;4:126-36. 
51. Foppa L, Caldara FR, Machado SP, Moura R, Santos RKS, Nääs IA, et al. Enriquecimento ambiental e comportamento de suínos: revisão/environmental enrichment and behaviour of pigs. Rev Bras Eng Biossist. 2014;8:1-7.

Recebido em: 17/07/2020

Aceito em: 19/11/2020

Stella AE, Oliveira AF, Moreira CN, Viali KG. Uso de antimicrobianos na suinocultura: Indicações e Restrições. Vet. e Zootec. 2020 ; 27: 001-014. 